\title{
sala de armas
}

(El proyecto y dirección de las obras ha estado a cargo de la Secretaría de Obras Públicas)

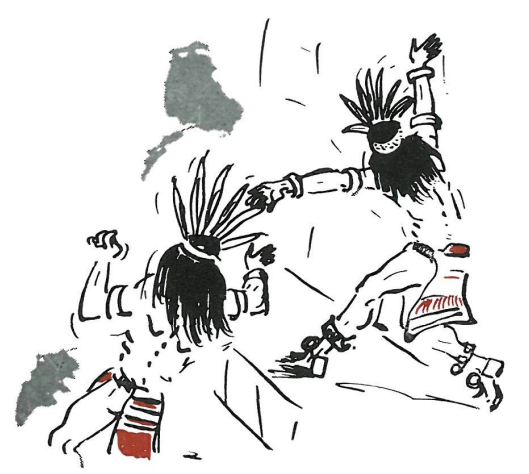

\section{simopsis}

Consta de dos plantas: la inferior alberga los servicios generales de la edificación y la cancha de competiciones, que cuenta con 18 pistas; en la superior se distribuyen las tribunas.

Esta instalación deportiva, con capacidad para alojar 3.254 espectadores, está situada a $22 \mathrm{~km}$ de la Villa Olímpica, en la zona norte de la Ciudad Deportiva "Magdalena Mixhuca".

En la zona norte de la Ciudad Deportiva «Magdalena Mixhuca», al sureste del cruce del Viaducto Miguel Alemán y Avenida Río Churubusco, a unos $22 \mathrm{~km}$ de la Villa Olímpica y a 8,1 $\mathrm{km}$ de la Plaza de la Constitución - Plaza Mayor-, fue construida esta instalación deportiva.

Tiene planta rectangular, con $95,20 \mathrm{~m}$ de longitud y $65 \mathrm{~m}$ de anchura.

Consta de dos plantas: en la inferior fueron instalados los servicios y el área de competiciones; y en la superior se han dispuesto las tribunas.

Las 3.254 localidades - que es el aforo total- se distribuyen: 2.273 para el público; 26 en el palco presidencial; 42 en la tribuna A, azul; 65 en la tribuna B, gris; 58 en la tribuna C, rojo; 36 en la tribuna D, amarillo; 162 para periodistas con mesa; 98 para radio y T.V.; 26 para fotógrafos; 286 en la tribuna $\mathrm{E}$, verde; 408 en la tribuna $\mathrm{F}$, café; y 50 en otras zonas.

El área de competiciones cuenta con 18 pistas.
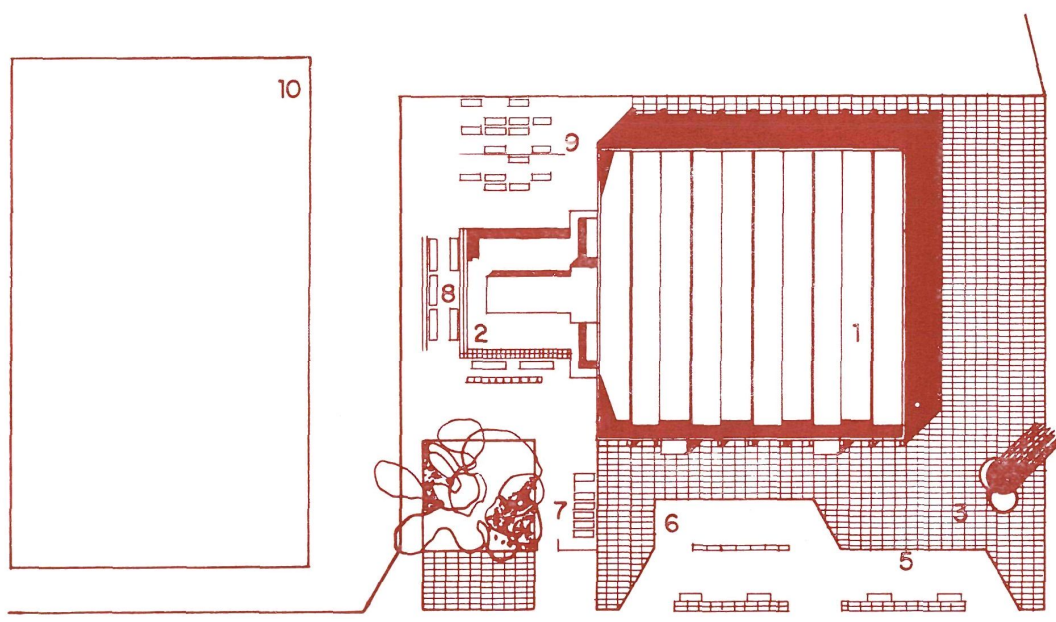

planta general
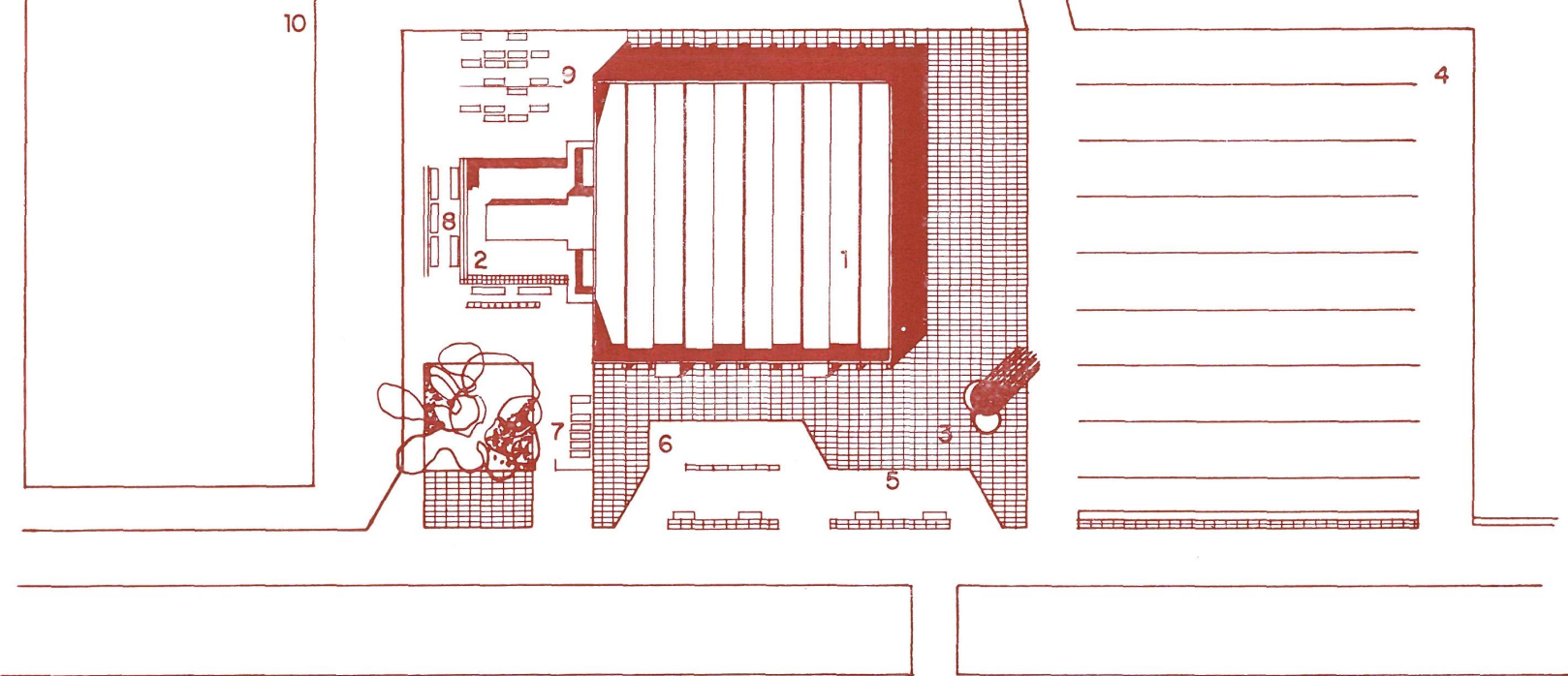

1. Gimnasio.-2. Servicios de atletas. - 3. Plaza.-4. Plaza actual de acceso y posible estacionamiento público.-5. Estacionamiento de taxis. - 6. Estacionamiento del C.O.I.-7. Estacionamiento de federaciones.-8. Estacionamienfútbol.

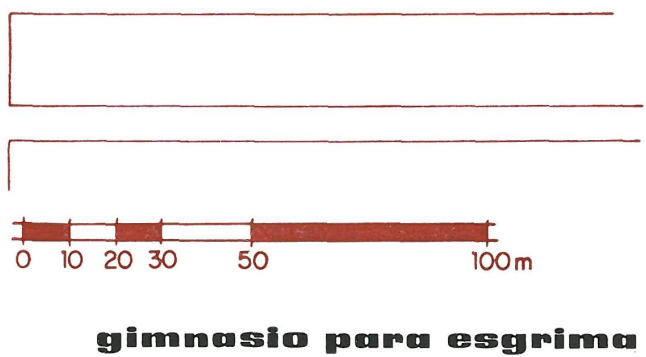


La edificación alberga también una serie de servicios, tales como: baños, sauna, vestuarios, restaurante, enfermería, sala de reposo, taller para armas, zona para los esgrimistas, y asientos para los competidores que esperan.

Como servicios especiales para la preparación del Certamen Olímpico fueron organizados: una Secretaría General, con $26,25 \mathrm{~m}^{2}$; una oficina para la Federación Internacional de Esgrima, con $16 \mathrm{~m}^{2}$; una sala de reunión del Jurado de Apelación, con $63 \mathrm{~m}^{2}$; el Directorio Técnico y Secretaría, con $32 \mathrm{~m}^{2}$; y la Sección de Verificación, con $14 \mathrm{~m}^{2}$; además de las correspondientes oficinas y zonas de trabajo, destinadas a la prensa, radio y T.V.

plantas

trilbunas

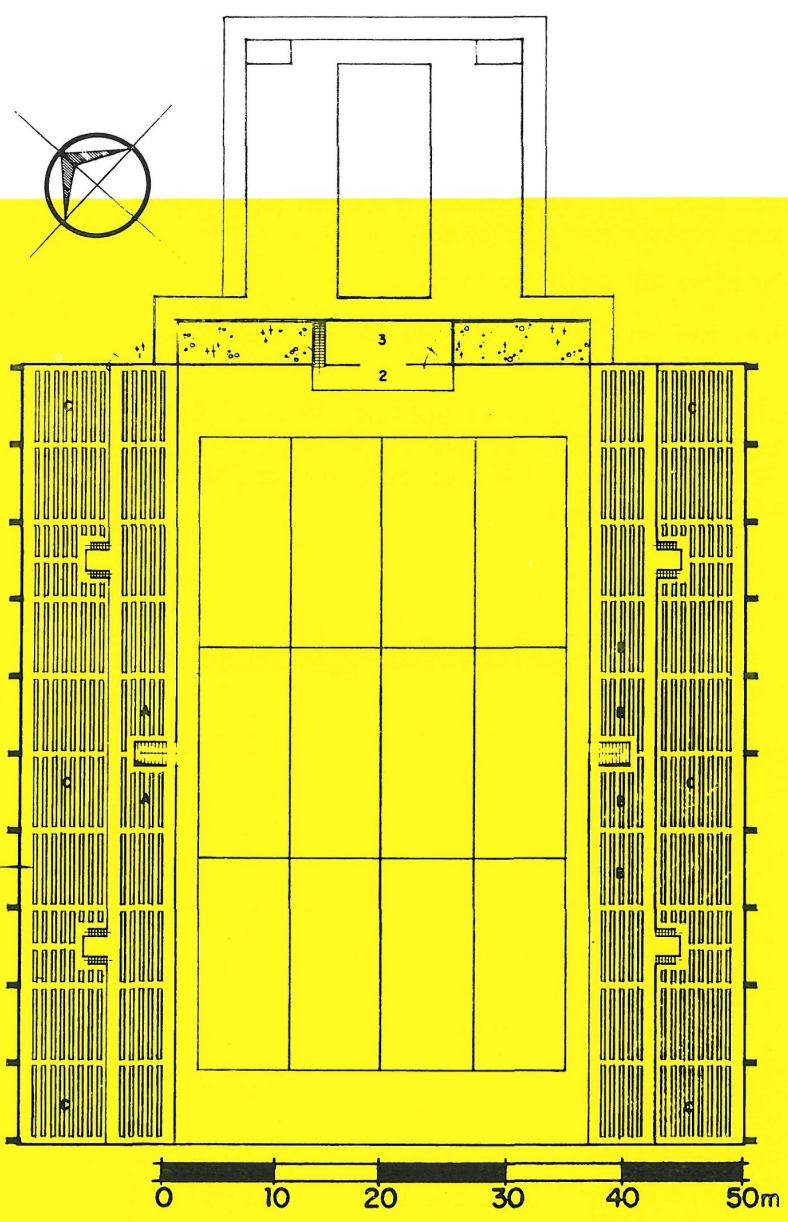

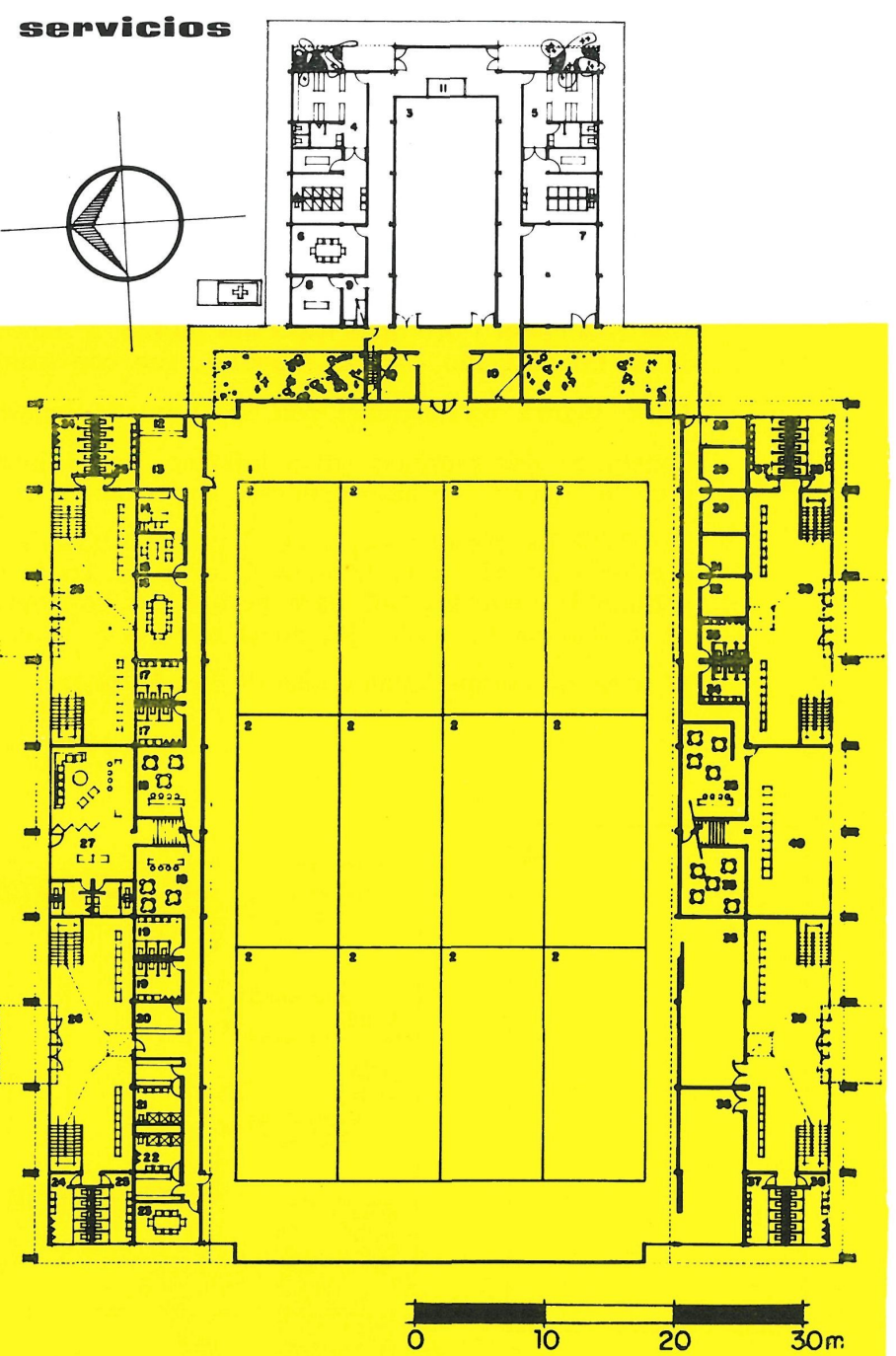

1. Escenario.-2. Canchas de esgrima.-3. Canchas de calentamiento.-4. Vestuarios y aseos atletas masculinos.-5. Vestuarios y aseos atletas femeninos.-6. Sala de Juntas.-7. Cuarto de máquinas.-8. Enfermeria.-9. Cuarto de reposo.-10. Concentración de atletas.-11. Control de atletas.-12. Control dirección del evento. 13. Espera.-14. Secretaria.-15. Privado director del evento.-16. Sala de Juntas.-17. Sanitarios para hom 1 . V y 26. Vestíbulo público--27. Antepalco del C.O.I-28. Control de radio, prensa y Tublico femenino.de radio.-30. Entrevistas de T.V.-31. Cuarto de radio.-32. Cuarto de T.V.-33. Sanitarios masculinos. 34. Sanitarios femeninos.-35. Bar-cafetería.-36. Bodega.-37. Sanitarios para público femenino.-38. Sanitarios para público masculino.-39. Vestíbulo para el público.-40. Zona de trabajo de prensa.

2. Escenario.

3. Bodega orquesta.

A) Tribunas para el C.O.I.

B) Tribunas para radio, prensa y T.V.

C) Tribuna pública. 